\title{
PRODUÇÃO DE CARVÃO ATIVADO A PARTIR DA CASCA DE CAFÉ
}

\author{
G. B. SANTOS ${ }^{1}$, L. D. TEDESCO ${ }^{1}$, R. T. RAVANI ${ }^{1}$, T. R. A. FRAGA ${ }^{1}$, M. R. T. HALASZ \\ ${ }^{1}$ FAACZ - Faculdades Integradas de Aracruz, Curso de Engenharia Química \\ E-mail para contato: halasz@fsjb.edu.br
}

\begin{abstract}
RESUMO - O presente estudo tem por objetivo a produção de carvão ativado a partir da casca de café, visando sua aplicação para a remoção do corante azul de metileno em soluções aquosas. Foram preparados carvões ativados utilizando como agente ativante o ácido fosfórico, em diferentes temperaturas $(450 ; 600 ; 750$ $\left.{ }^{\circ} \mathrm{C}\right)$ e tempos de ativação $(1,5 ; 2,5 ; 3,5$ h). A partir dos ensaios de adsorção, verificou-se que o melhor material foi aquele preparado a temperatura de $750{ }^{\circ} \mathrm{C}$ e tempo de 3,5 h, apresentando uma capacidade de remoção do corante correspondente a $417,87 \mathrm{mg} \cdot \mathrm{g}^{-1}$, enquanto que o carvão ativado comercial (Cromoline Química Fina) apresentou uma capacidade de remoção de 156,71 mg. $\mathrm{g}^{-1}$. A partir da análise MEV realizada para a casca de café e para os carvões ativados (comercial e o carvão ativado produzido promissor), observou-se que o carvão ativado produzido apresentou uma estrutura mais porosa, quando comparado ao material precursor e ao carvão ativado comercial.
\end{abstract}

\section{INTRODUÇÃO}

A casca de café é um dos principais resíduos agrícolas gerados no Brasil, que apesar de possuir algumas aplicações, grande parte da mesma ainda é desprezada. Uma forma de reaproveitar a casca de café é utilizando-a como matéria-prima para a produção de carvão ativado, o qual por sua vez, é um material de maior valor agregado (PEREIRA, 2010; OLIVEIRA et al., 2008).

De acordo com Claudino (2003), carvão ativado é definido como um material carbonáceo que sofreu um processamento com a finalidade de aumentar sua porosidade interna, conferindo a capacidade de adsorver moléculas ou impurezas no interior de seus poros (os quais são classificados como sendo macro, meso ou microporos). Em sua produção, o carvão ativado pode ser obtido pelo processo de ativação química ou física. A ativação química consiste na impregnação de agentes ativantes, sobre o material ainda não pirolisado, com subseqüente carbonização e pirólise. (KHALILI et al., 2000). A ativação física consiste na gaseificação do material carbonizado através de sua oxidação com gases (vapor d'água, $\mathrm{CO}_{2}$, ar ou junção destes gases) a temperaturas entre $800{ }^{\circ} \mathrm{C}$ a $1000{ }^{\circ} \mathrm{C}$ (RODRÍGUEZ; MOLINA, 1998). Quanto a sua aplicação, o carvão ativado é um adsorvente muito utilizado na indústria, como por exemplo, para a remoção de corantes presentes em efluentes industriais. Diversos corantes podem ser utilizados em testes de adsorção, entretanto, o corante orgânico azul de metileno é o mais utilizado, devido ao fato de apresentar uma forte adsorção em suportes sólidos (FUNGARO; IZIDORO; BRUNO, 2009). 
Tendo em vista a grande quantidade de casca de café desprezada, e a possibilidade de reaproveitar esta biomassa para a produção de material de maior valor agregado, o presente trabalho objetiva a produção de carvão ativado a partir da casca de café, visando a sua aplicação para a remoção do corante azul de metileno.

\section{MATERIAIS E MÉTODOS}

A casca de café utilizada no trabalho foi coletada na Cafeeira Cuzzuol Pimentel, localizada no município de Aracruz - ES, sendo a mesma obtida por processamento via seca.

\subsection{Preparação da Biomassa}

O procedimento foi realizado com base no trabalho de Bianchi et al. (2008), onde a casca de café foi triturada e peneirada, resultando numa granulometria entre 250 a $297 \mu \mathrm{m}(48$ a 60 mesh).

\subsection{Produção de Carvão Ativado}

Para a produção do carvão ativado, optou-se pelo processo de ativação química, onde foi utilizado o ácido fosfórico $\left(\mathrm{H}_{3} \mathrm{PO}_{4}\right)$ como agente ativante, adotando-se três temperaturas $\left(450,600,750{ }^{\circ} \mathrm{C}\right)$ e três tempos de ativação $(1,5 ; 2,5$ e $3,5 \mathrm{~h})$.

Inicialmente, a casca de café triturada foi impregnada com o agente ativante na proporção 1:1 em massa (agente ativante:casca) e colocados em uma estufa a $110{ }^{\circ} \mathrm{C}$, onde permaneceu por um período de $24 \mathrm{~h}$. Posteriormente, o material foi pirolisado em um forno mufla (Sppencer Scientific), sob atmosfera inerte, com fluxo de $100 \mathrm{~mL} \mathrm{~min}{ }^{-1}$ de argônio (RAMOS et al., 2009), onde o material foi submetido a variações de temperatura e tempo. Após a ativação, o carvão ativado foi lavado com água destilada, até pH neutro, para a remoção do agente ativante e desobstrução dos poros formados.

\subsection{Teste de Adsorção}

Os estudos de adsorção foram realizados em duplicata, tanto para os carvões ativados produzidos, quanto para o carvão ativado comercial do fabricante Cromoline Química Fina LTDA.

Para a obtenção das isotermas de Langmuir, $30 \mathrm{mg}$ dos materiais adsorventes foram colocados em contato com $30 \mathrm{~mL}$ das soluções aquosas de azul de metileno nas concentrações de $25,50,100,250$ e $500 \mathrm{mg} . \mathrm{L}^{-1}$, permanecendo em agitação por um período de 24 horas, à temperatura ambiente (PEREIRA, 2010). Em seguida, as suspensões foram centrifugadas e os sobrenadantes foram analisados por espectrofotometria UV-visível (Spectrum, SP-2000UV), no comprimento de onda de $645 \mathrm{~nm}$ (OLIVEIRA et al., 2009). 
De acordo com Chowdhury (2012), pode-se calcular a capacidade de adsorção do adsorvente em qualquer concentração de uma fase líquida, através da Equação 1:

$$
Q_{e q}=\left(C_{0}-C_{e q}\right) \times V / m
$$

Sendo $\mathrm{Q}_{\mathrm{eq}}$ a quantidade de corante adsorvida pelos adsorventes (mg.g-1); $\mathrm{C}_{0}$ a concentração inicial da solução de corante $\left(\mathrm{mg} . \mathrm{L}^{-1}\right) ; \mathrm{C}_{\mathrm{eq}}$ a concentração de corante no equilíbrio (mg. $\left.\mathrm{L}^{-1}\right)$; V o volume da solução de corante (L) e m a massa de adsorvente (g).

\subsection{Microscopia Eletrônica de Varredura (MEV)}

A morfologia da casca de café, da amostra mais promissora de carvão ativado produzido e do carvão ativado comercial, foi determinada por microscopia eletrônica de varredura, em um equipamento ZEISS EVO MA10, empregando uma tensão de $20 \mathrm{kV}$. Os materiais estudados foram colados em um suporte de alumínio, utilizando-se fita dupla-face de carbono e, em seguida, foram cobertos com uma fina camada de ouro em um evaporador (modelo Quorum, Q15ORES).

\section{RESULTADOS E DISCUSSÕES}

\subsection{Teste de Adsorção}

A partir dos dados experimentais dos testes de adsorção, foi possível obter as isotermas de adsorção do corante azul de metileno. As mesmas foram determinadas plotando-se o gráfico da quantidade adsorvida $\left(\mathrm{Q}_{\text {eq }}\right)$ em função da concentração de equilíbrio da espécie em solução $\left(\mathrm{C}_{\mathrm{eq}}\right)$.

Figura 1 - Isotermas de adsorção adequadas ao modelo de Langmuir, para os carvões ativados preparados a temperatura de (A) $450{ }^{\circ} \mathrm{C}$, (B) $600^{\circ} \mathrm{C}$ e (C) $750^{\circ} \mathrm{C}$, nos tempos de (•) $1,5 \mathrm{~h}$,

(匹) $2,5 \mathrm{~h},(\mathbf{\Delta}) 3,5 \mathrm{~h}$.
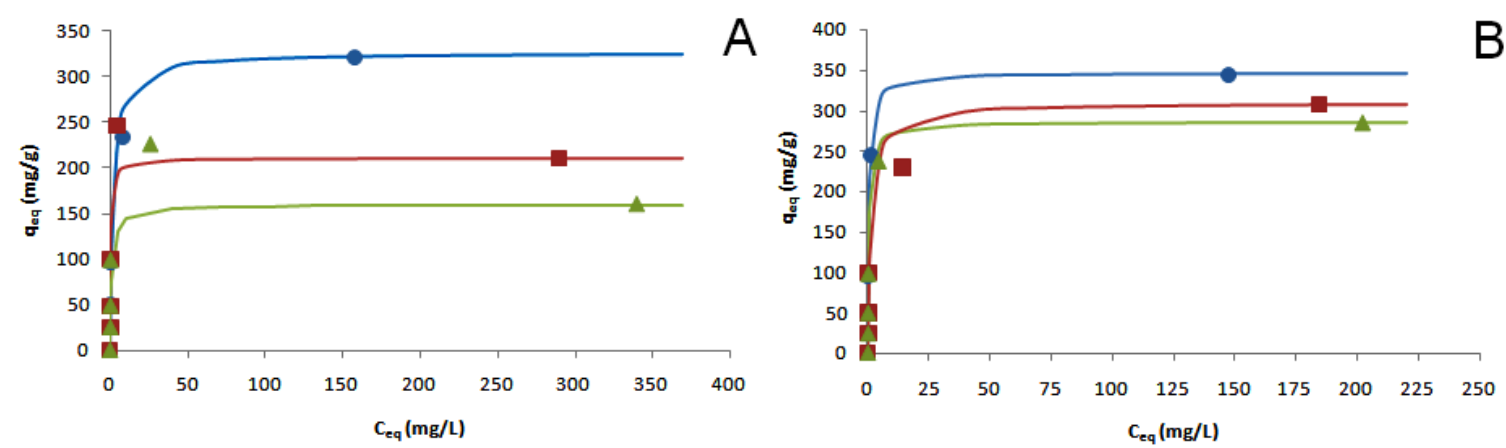


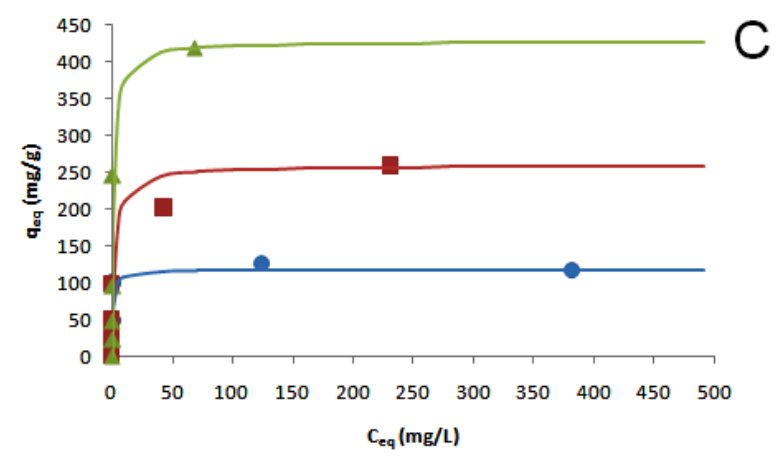

A partir da Figura 1, pode-se observar os valores máximos de $\mathrm{Q}_{\mathrm{eq}}$ das isotermas. $\mathrm{Na}$ Figura 1.A, o maior valor de $\mathrm{Q}_{\mathrm{eq}}$ encontrado foi de $321,03 \pm 2,00 \mathrm{mg} . \mathrm{g}^{-1}$, que correspondeu ao carvão ativado produzido a $450^{\circ} \mathrm{C}$ e $1,5 \mathrm{~h}$. Na Figura 1.B, o maior valor de $\mathrm{Q}_{\text {eq }}$ encontrado foi de $344,33 \pm 28,13 \mathrm{mg} . \mathrm{g}^{-1}$, que correspondeu ao carvão ativado produzido a $600^{\circ} \mathrm{C}$ e $1,5 \mathrm{~h}$. Na Figura 1.C, o maior valor de $\mathrm{Q}_{\text {eq }}$ encontrado foi de 417,87 $\pm 6,04 \mathrm{mg} \cdot \mathrm{g}^{-1}$, que correspondeu ao carvão ativado produzido a $750^{\circ} \mathrm{C}$ e $3,5 \mathrm{~h}$.

Sendo assim, para o conjunto de carvões ativados produzidos, o que apresentou a maior capacidade de adsorção foi o produzido a temperatura de $750{ }^{\circ} \mathrm{C}$ e tempo de ativação de $3,5 \mathrm{~h}$, sendo este comparado ao carvão ativado comercial, conforme observado pela Figura 2.

Figura 2 - Isotermas de adsorção do $(\boldsymbol{\Delta})$ carvão ativado produzido à temperatura de $750{ }^{\circ} \mathrm{C} \mathrm{e}$ tempo de 3,5 h e do ( $\bullet$ carvão ativado comercial.

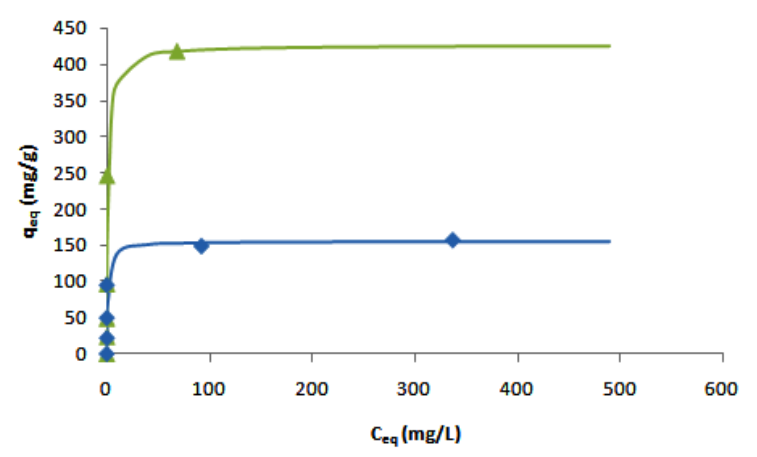

Na Figura 2, é possível observar que o carvão ativado produzido apresentou maior capacidade de adsorção (417,87 mg.g $\left.{ }^{-1}\right)$, quando comparado ao carvão ativado comercial $\left(156,71 \mathrm{mg} \cdot \mathrm{g}^{-1}\right)$. A alta capacidade de adsorção obtida para o carvão ativado produzido a partir da casca de café pode estar associada à morfologia deste material, uma vez que materiais com estruturas altamente porosas apresentam capacidades elevadas de adsorção.

\subsection{Microscopia Eletrônica de Varredura}

A Figura 3.a apresenta a micrografia da casca de café antes do processo de carbonização, a Figura 3.b apresenta o carvão ativado produzido a partir da casca de café e na Figura 3.c pode-se observar o carvão ativado comercial do fabricante Cromoline. 
Figura 3 - Micrografias do (a) casca de café (b) carvão ativado produzido (c) carvão ativado comercial a $1000 x$.

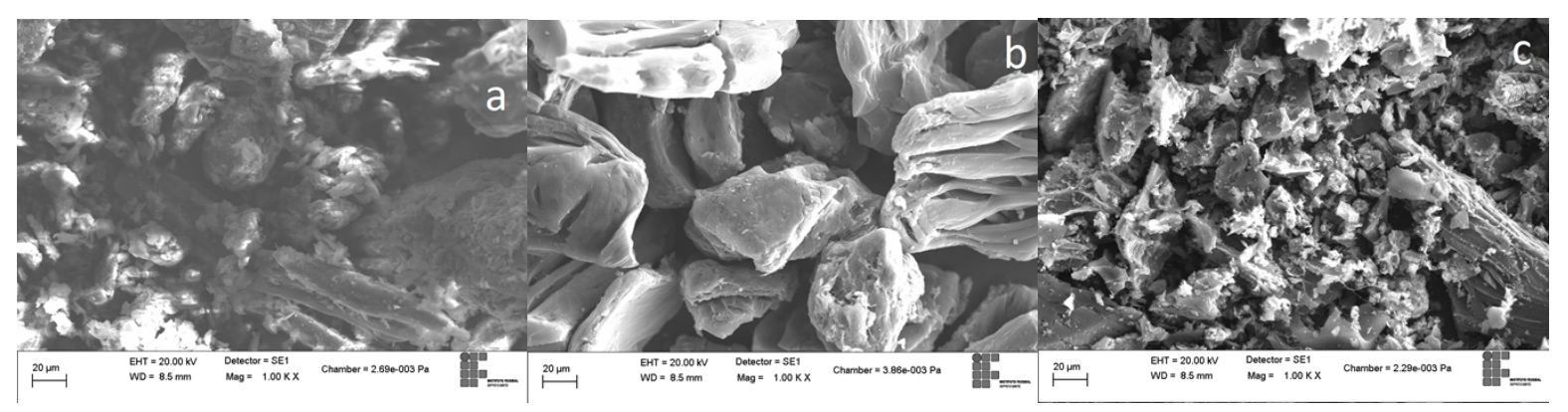

Nas Figuras 3.a e 3.b, nota-se um aumento na porosidade promovido pelo processo de ativação, da casca de café para o carvão ativado produzido a partir deste precursor. $\mathrm{O}$ aumento do número de poros pode fornecer uma maior área de deposição ao material, explicando assim, a elevada capacidade de adsorção apresentada pelo carvão ativado produzido a partir da casca de café.

A partir das Figuras 3.b e 3.c, observa-se que ambos os carvões ativados apresentam uma estrutura porosa, bem definida e irregular. No entanto, o carvão ativado produzido a partir da casca de café aparenta possuir poros maiores quando comparado ao carvão ativado comercial. Comparativamente ao carvão ativado comercial, os poros apresentados pelo carvão ativado produzido a partir da casca de café se mostraram mais favoráveis para a adsorção de moléculas grandes, como a do corante azul de metileno. Este fato pode ser confirmado pelos resultados do teste de adsorção apresentados, anteriormente, para ambos os carvões ativados.

\section{CONCLUSÃO}

O estudo revelou que, dentre os carvões ativados obtidos a partir do ácido fosfórico, a amostra mais promissora foi àquela preparada à temperatura de $750^{\circ} \mathrm{C}$ e tempo de ativação de 3,5 h. Nestas condições, o material apresentou uma capacidade de remoção de azul de metileno correspondente a 417,87 mg. $\mathrm{g}^{-1}$, que se mostrou muito superior à capacidade do carvão ativado comercial, que foi de apenas $156,71 \mathrm{mg} \cdot \mathrm{g}^{-1}$.

A partir da análise morfológica dos materiais, observou-se que a alta capacidade de adsorção do corante azul de metileno para o carvão ativado produzido a partir da casca de café está associada à estrutura altamente porosa que o mesmo adquiriu após a biomassa ter sido submetida a um processo de ativação química.

Diante dos resultados favoráveis obtidos, conclui-se que a casca de café pode ser utilizada para a produção de carvão ativado, contribuindo assim para a redução dos custos no processo de obtenção deste carvão e minimização dos impactos ambientais causados pelo despejo incorreto de resíduos provenientes da produção agrícola do café. 


\section{REFERÊNCIAS}

BIANCHI, M. L.; BRUM, S. S.; SILVA, V. L da.; GONÇALVES, M.; GUERREIRO, M. C.; OLIVEIRA, L. C. A. de. Preparação e caracterização de carvão ativado produzido a partir de resíduos do beneficiamento do café. Química Nova, Lavras, v. 31, n. 05, p. 1048-1052, 2008

CHOWDHURY, Z. K.; SUMMERS, R. S.; WESTERHOFF, G. P.; LETO, B. J.; NOWACK, K. O.; CORWIN C. J. Activated Carbon: Solutions for improving water quality. [S.1]: American Water Works Association, 2012.

CLAUDINO, A. Preparação de carvão ativado a partir de turfa e sua utilização na remoção de poluentes. 2003. 101 f. Dissertação (Mestrado em Engenharia Química) PPGEQ, Universidade Federal de Santa Catarina. Florianópolis.

FUNGARO, D. A; IZIDORO, J. C.; BRUNO, M. Aplicação de material zeolítico sintetizado de cinzas de carvão como adsorvente de poluentes em água. Eclética Química, São Paulo, v. 34, n. 01, p. 45-50, 2009.

KHALILI, R. N.; CAMPBELL, M.; SANDI, G.; GOLAS, J. Production of micro and mesoporous activated carbon from paper mill sludge: I. Effect of zinc chloride activation. Carbon, Oxford, v. 38, n. 14, p. 1905-1915, 2000.

OLIVEIRA, L. C. A.; PEREIRA, E.; GUIMARÃES, I.; VALlONE，A.; SAPAG，K.; PEREIRA, M.; MESQUITA, J. P. Preparation of activated carbons from coffee husks utilizing $\mathrm{FeCl}_{3}$ and $\mathrm{ZnCl}_{2}$ as activating agents. J. Hazard. Mater., [S. 1], v. 165, p. 87-94, 2009.

OLIVEIRA, L. C. A.; PEREIRA, E.; VALLONE, A.; SAPAG, K.; PEREIRA, M. Preparação de carvão ativado em baixas temperaturas de carbonização a partir de rejeitos de café: utilização de $\mathrm{FeCl}_{3}$ como agente ativante. Química Nova, [S.1.], v. 31, n. 06, p. 12961300, 2008.

PEREIRA, E. I. Produção de carvão ativado a partir de diferentes precursores utilizando $\mathbf{F e C l}_{3}$ como agente ativante. 2010. 90 f. Dissertação (Mestrado em Agroquímica) PPGA, Universidade Federal de Lavras. MG.

RAMOS, P. H.; GUERRIRO, M. C.; RESENDE, E. C. de; GONÇALVES, M. Produção e caracterização de carvão ativado produzido a partir do defeito preto, verde, ardido (PVA) do café. Química Nova, Lavras, v. 32, n. 05, p. 1139-1143, 2009.

RODRÍGUEZ, F. R.; MOLINA, M. S. Textural and chemical characterization of microporous carbons. Advances in Colloid and Interface Science, Seattle, v. 76/77, p. 271-294, 1998. 